\title{
Prediction of Surface Roughness and Optimization of Process Parameters for Slow Tool Servo Turning
}

\author{
Hangyan Guo (0000-0002-4364-4004), Min Kang(0000-0001-6864-7802), Wei Zhou(0000-0001-5233-908X) \\ College of Engineering, Nanjing Agricultural University, No.40, Dianjiangtai Road, Pukou Distinct, Nanjing \\ 210031. China. Email:2019112003@njau.edu.cn, kangmin@njau.edu.cn,1506036510@qq.com
}

Surface roughness is an important index to evaluate the quality of a machined surface. In order to accurately predict the surface roughness for slow tool servo (STS) turning, taking toric surface as an example, response surface methodology (RSM) was used to perform the process test. The second-order response surface prediction model was established and the variance analysis and reliability test were carried out. The results showed that the average prediction error was 7.6\%. In order to obtain the best process parameters, standard particle swarm optimization (PSO) was used. The results showed that the global optimization ability of standard PSO was poor. In order to solve the problem, compression factor was introduced and particle swarm optimization with compression factor (WCF-PSO) was constructed, which enhanced the convergence of PSO effectively. WCF-PSO was used to optimize the process parameters and the results obtained were $R_{f}=0.87 \mathrm{~mm}, a_{f}=0.01 \mathrm{~mm} / \mathrm{r}, a_{p}=0.05 \mathrm{~mm}, \Delta \theta=8.70^{\circ}$, with a corresponding surface roughness of $R a=0.0486 \mu \mathrm{m}$. The results of the verification test showed that the actual value was $R a=0.0520 \mu \mathrm{m}$, and the error was only $7.0 \%$, indicating that WCF-PSO had a better optimization effect.

Keywords: Slow tool servo, Response surface methodology, Prediction model, Particle swarm optimization, Optimization of process parameters

\section{Introduction}

Compared with ordinary optical surfaces, complex optical surfaces have unique optical properties, such as simplifying the optical system and optimizing the imaging quality, so they are widely used in many fields [1-6]. For example, toric surface is a typical aspheric complex optical surface, which has good optical properties and can form different diopters in two perpendicular directions [7]. Based on this feature, toric surface lenses are widely used to correct astigmatism. However, the traditional turning process is difficult to meet the quality requirements of complex optical surfaces (such as toric surfaces), which limits their application. As a new ultra-precision machining method, STS turning technology has good machining quality. In recent years, it has been applied to the turning of

various complex optical surfaces [8-10].

Surface roughness is one of the important indexes used to evaluate the surface machining quality. It is of great practical value to accurately predict and control the surface roughness for STS turning [11]. Lin et al. [12] carried out simulation experiments using Matlab software and established the surface topography prediction model of ultra precision machining microlens array. However, due to various errors in actual machining, the simulation experiments could not reflect the real results well. Wang et al. [13] established the surface roughness prediction model of LS-SVM based on radial basis function by using orthogonal regression analysis and least squares support vector machine, but did not get the best process parameters. Shi et al. [14] established the surface roughness prediction model by using orthogonal regression analysis method and RSM respectively. The results showed that the prediction accuracy of the second-order response surface method was better than that of the orthogonal regression analysis method, but the process parameters were also not optimized. The optimal process parameters can improve the processing quality or efficiency, which has practical significance to guide production. Therefore, it is necessary to optimize the process parameters [15]. Lin et al. [16] optimized the mathematical model of surface roughness using satisfaction function method, but the parameter estimation of this method is uncertain [17], so it is not easy to obtain the optimal process parameters. Wei et al. [18] optimized the process parameters of piezoelectric vibration energy recovery device using standard PSO, and obtained the best process parameters under different modes, but the standard PSO is easy to fall into local optimum position.

According to the research and analysis above, the turning test was designed based on RSM in this paper. Four main cutting parameters of tool tip radius $\left(R_{t}\right)$, feed rate $\left(a_{f}\right)$, cutting depth $\left(a_{p}\right)$ and discrete angle $(\Delta \theta)$ were taken as independent variables, and surface roughness $(R a)$ was taken as dependent variable. The se- 
cond-order response surface prediction model was established, and the variance analysis and reliability test of the model were carried out. In order to obtain the best process parameters, standard PSO was improved. Compression factor was introduced into standard PSO. Particle swarm optimization with compression factor (WCF-PSO) was used to optimize the process parameters, and the best combination of process parameters was obtained. The results of the verification test showed that WCF-PSO proposed in this paper had a better optimization effect.

\section{STS machining toric surface}

\subsection{Principle and experimental device}

STS turning is a new ultra-precision turning technology, which is mainly used in the precision machining of complex optical surfaces. Figure 1 shows the STS turning platform with high precision developed by our own laboratory. Its layout is ' $\mathrm{T}$ ' shaped, and it mainly consists of two linear motion axes ( $\mathrm{X}$-axis and $\mathrm{Z}$-axis) and a rotary motion axis (C-axis). The $\mathrm{X}$-axis and $\mathrm{Z}$-axis are driven by two linear motors respectively (The type of the linear motors is $S W I 225 \mathrm{LM}$, and the positioning accuracy is $\pm 1 \mu \mathrm{m})$, and the $\mathrm{C}$-axis is driven by a precision pneumatic motorized spindle (The model of the spindle is ZCS-150QD01, which has a highest rotational speed of $1000 \mathrm{rpm}$, and its radial jump is less than $0.1 \mu \mathrm{m})$. In addition, the tool holder is installed on the Z-axis with good dynamic performance, and the PCD tool is installed on the tool holder. Among them, the $\mathrm{C}$-axis drives the workpiece to rotate, the $\mathrm{X}$-axis drives the tool to feed along the $\mathrm{X}$ direction, and the $\mathrm{Z}$-axis drives the tool to reciprocate along the $\mathrm{Z}$ direction. The three-axis linkage drives the tool to perform spatial spiral cutting motion relative to the end face of the workpiece, realizing the processing of various complex surfaces [19].

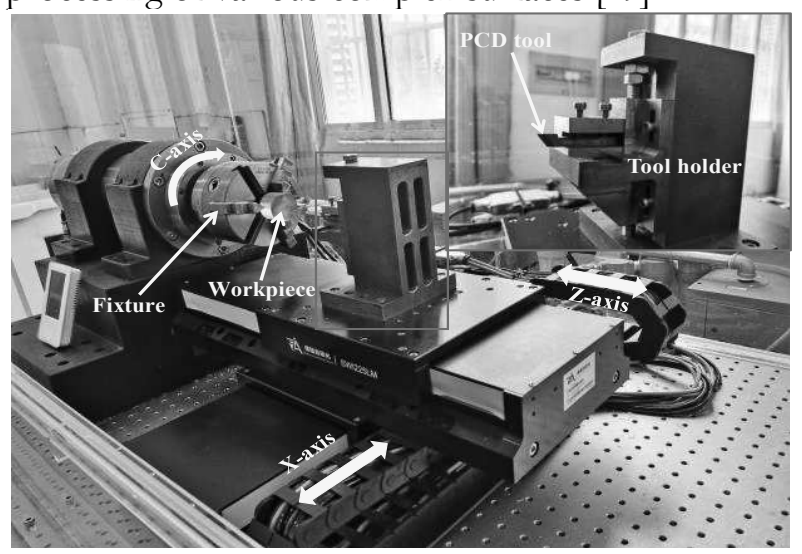

Fig. 1 STS turning platform with high precision

\subsection{Toric Surface and Machining Method}

Toric surface is a typical aspheric complex optical surface, that has good optical properties and its mathematical equation can be expressed by formula (1).
Toric surface is a surface obtained by rotating a base circle with radius $a$ around the axis in the plane of the base circle but not through the center of the base circle with radius $R_{H}$, as shown in Figure 2 . Where $R_{H}$ is the radius of orthogonal arc, $a$ is the radius of base arc, and $R_{H}>_{a}$ [20].

$$
z=R_{H}+a-\sqrt{\left(R_{H}+\sqrt{a^{2}-y^{2}}\right)^{2}-x^{2}}
$$

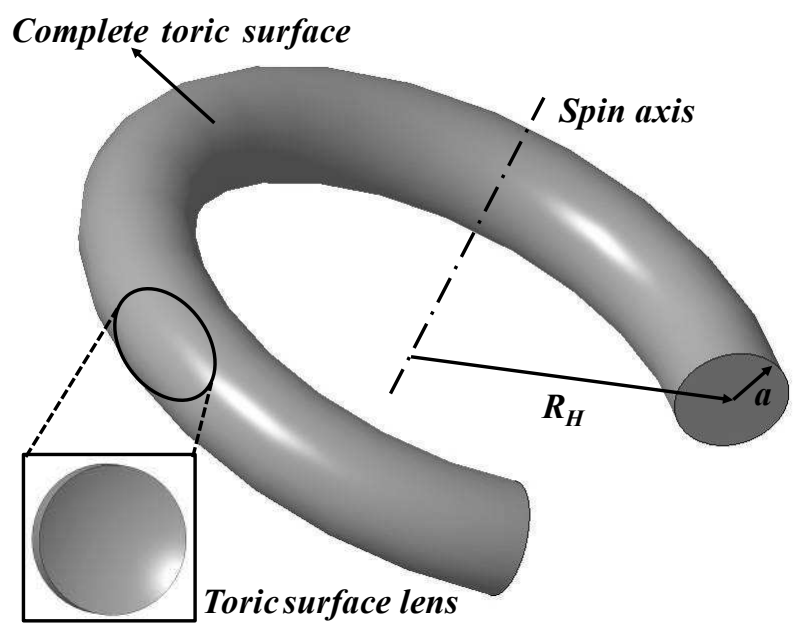

Fig. 23D diagram of toric surface

STS turning technology was used to process the toric surface lenses, and the typical spiral path was selected as the tool path [21]. Equal angle discretization method was adopted, and the equation of cutting contact points (CCPs) trajectory can be shown in formula (2) [22]:

$$
\left\{\begin{array}{l}
x=\frac{a_{f}}{2 \pi} \theta_{i} \cos \theta_{i} \\
y=\frac{a_{f}}{2 \pi} \theta_{i} \sin \theta_{i} \quad(i=1,2, \ldots) \\
z=f(x, y) \\
\theta_{i}=(i-1) \Delta \theta
\end{array}\right.
$$

Where, $(x, y, z)$ is the coordinate of the CCP in rectangular coordinate system, $z=f(x, y)$ is the equation of complex surface, $a_{f}$ is the feed rate, $\theta_{i}$ is the positive angle between the connection line from the CCP to the center of the workpiece and the $\mathrm{X}$-axis in the XOY plane, and $\Delta \theta$ is the discrete angle [22]. The trajectory of cutting location points (CLPs) can be obtained after the CCPs are compensated by tool compensation algorithm (Z-direction compensation) [23], as shown in Figure 3. Where, $R_{t}=0.5 \mathrm{~mm}$, $\Delta \theta=6^{\circ}$, and $a_{f}=1 \mathrm{~mm}$. The material of workpiece is polymethyl methacrylate (PMMA), and the diameter is $D=0.5 \mathrm{~mm}$. When machining, the tool cut in from the outer edge of the workpiece. 


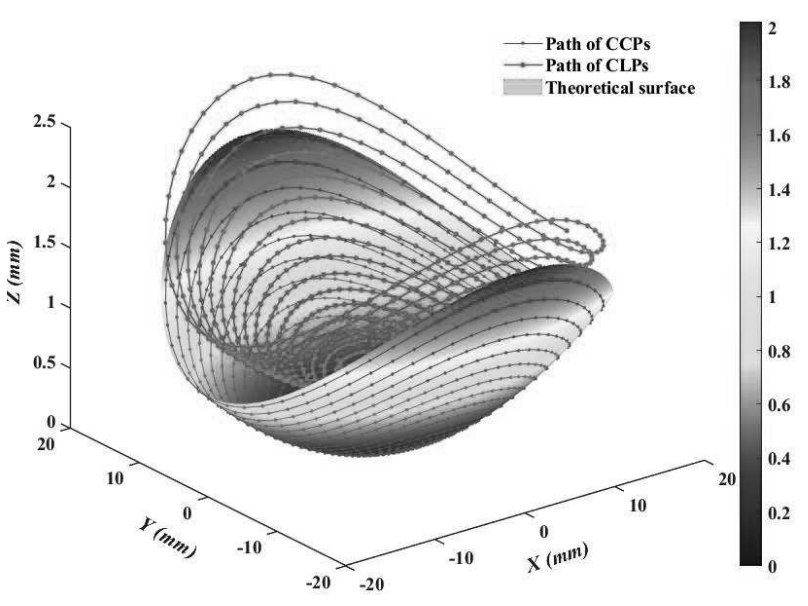

Fig. 3 Tool path of turning toric surface

\section{Process test and model establishment}

\subsection{Test scheme and results}

The central composite design (CCD) method in classical RSM was used to design the experiment. The response was surface roughness $(R a)$, and the four parameters that have a relatively large influence on the surface quality of STS turning were selected as factors.

They were tool tip radius $\left(R_{t}\right)$, feed rate $\left(a_{f}\right)$, cutting depth $\left(a_{p}\right)$ and discrete angle $(\Delta \theta)$ respectively. 5 levels $(-a,-1,0,1, a)$ were set for each factor, where $a$ was the value of rotation factor, and it can be determined by the formula $a=2^{k / 4}$ ( $k$ is the number of factors, and there were 4 factors in this test, so $k=4$ ) [24]. The rotation design of RSM had the property of constant prediction variance at the equidistant point of the design center by selecting the reasonable value of the rotation factor $a$, which improved the prediction accuracy [24]. Table 1 is the factor level coding table for this test design.

After the machining of the workpieces of toric surface were completed, the JB-4C surface measurement system was used for measurement. Combined with figure 4, the measurement method of surface roughness was described as follows: 1) The workpiece was evenly divided into 8 parts along the circumferential direction and marked on the edge of the workpiece. 2) The probe of the surface measurement system measured the surface along these 8 lines. 3) The maximum and minimum values of the 8 results were removed, and the average of the remaining 6 results was calculated to obtain the final value of surface roughness. Table 2 shows the 26 groups of experimental data obtained by the method above.

Tab. 1 Factor level coding table

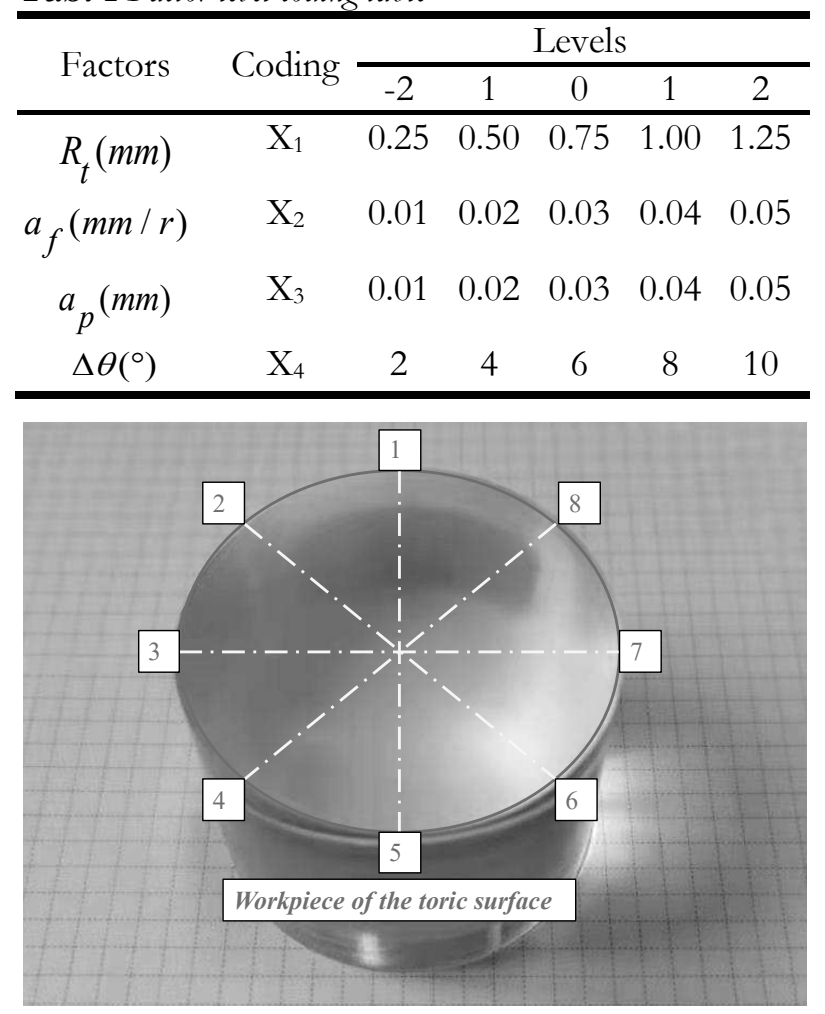

Fig. 4 Measurement method of surface roughness

Tab. 2 Experimental data

\begin{tabular}{cccccccccccc}
\hline $\begin{array}{c}\text { Num- } \\
\text { ber }\end{array}$ & $\begin{array}{c}R_{t} \\
(\mathrm{~mm})\end{array}$ & $\begin{array}{c}a_{f} \\
(\mathrm{~mm} / \mathrm{r})\end{array}$ & $\begin{array}{c}a_{p} \\
(\mathrm{~mm})\end{array}$ & $\begin{array}{c}\Delta \theta \\
\left({ }^{\circ}\right)\end{array}$ & $\begin{array}{c}\mathrm{R} a \\
(\mu \mathrm{m})\end{array}$ & $\begin{array}{c}\text { Num- } \\
\text { ber }\end{array}$ & $\begin{array}{c}R_{t} \\
(\mathrm{~mm})\end{array}$ & $\begin{array}{c}a_{f} \\
(\mathrm{~mm} / \mathrm{r})\end{array}$ & $\begin{array}{c}a_{p} \\
(\mathrm{~mm})\end{array}$ & $\begin{array}{c}\Delta \theta \\
\left({ }^{\circ}\right)\end{array}$ & $\begin{array}{c}\mathrm{R} a \\
(\mu \mathrm{m})\end{array}$ \\
\hline 1 & 0.50 & 0.04 & 0.04 & 8 & 0.1222 & 14 & 1.00 & 0.02 & 0.04 & 8 & 0.0680 \\
2 & 0.75 & 0.05 & 0.03 & 6 & 0.1053 & 15 & 0.75 & 0.01 & 0.03 & 6 & 0.0540 \\
3 & 1.00 & 0.04 & 0.02 & 8 & 0.0950 & 16 & 0.50 & 0.02 & 0.04 & 8 & 0.0952 \\
4 & 0.75 & 0.03 & 0.01 & 6 & 0.0727 & 17 & 0.75 & 0.03 & 0.05 & 6 & 0.0710 \\
5 & 0.75 & 0.03 & 0.03 & 6 & 0.0722 & 18 & 1.25 & 0.03 & 0.03 & 6 & 0.1180 \\
6 & 0.50 & 0.02 & 0.02 & 8 & 0.0872 & 19 & 0.50 & 0.04 & 0.02 & 8 & 0.1137 \\
7 & 1.00 & 0.02 & 0.02 & 8 & 0.0743 & 20 & 0.50 & 0.04 & 0.04 & 4 & 0.1102 \\
8 & 1.00 & 0.02 & 0.02 & 4 & 0.0725 & 21 & 1.00 & 0.04 & 0.04 & 4 & 0.0982 \\
9 & 0.75 & 0.03 & 0.03 & 2 & 0.0805 & 22 & 0.75 & 0.03 & 0.03 & 10 & 0.0743 \\
10 & 0.25 & 0.03 & 0.03 & 6 & 0.1612 & 23 & 0.50 & 0.02 & 0.04 & 4 & 0.1038 \\
11 & 0.50 & 0.04 & 0.02 & 4 & 0.1067 & 24 & 1.00 & 0.04 & 0.04 & 8 & 0.1058 \\
12 & 0.75 & 0.03 & 0.03 & 6 & 0.0685 & 25 & 1.00 & 0.04 & 0.02 & 4 & 0.0900 \\
13 & 0.50 & 0.02 & 0.02 & 4 & 0.0920 & 26 & 1.00 & 0.02 & 0.04 & 4 & 0.0683 \\
\hline
\end{tabular}




\subsection{Establishment of prediction model}

RSM is a kind of data processing method. The specific fitting method is to describe $n$ coordinates $\left(x_{i}, y_{i}\right)$

$$
f(x)=c_{0}+c_{1} \phi_{1}(x)+c_{2} \phi_{2}(x)+\cdots+c_{m} \phi_{2 m}(x)
$$

Where, $c_{0}$ is a constant, $c_{1}, c_{2}, \ldots, c_{m}$ are undetermined coefficients, and $\phi_{k}(x)$ is a kind of simple function, $(k=1,2, \ldots, m)$.

In order to make the constructed function $\phi_{k}(x)$ better reflect the overall shape of the responsding surface function $f(x)$, the function $\phi_{k}(x)$ is required to minimize the sum of squares $(R)$ of deviations at each point [26]: of sampling points in the coordinate system according to the observation data, $i=1,2, \ldots, n$, and then construct the responsding surface function [25]:

$$
\min R=\sum_{i=1}^{n}\left[\phi\left(x_{i}\right)-y_{i}\right]^{2}
$$

In this paper, the least square method was used to fit the response surface. RSM was used to approximate the relationship between design objective and variables, and the multiple regression equation was used to fit the functional relationship between influencing factors and response. The quadratic complete polynomial was selected as the constructor function $\phi_{k}(x)$ to form a typical second-order response surface model [27]:

$$
f(x)=c_{0}+\sum_{i=1}^{k} c_{i} x_{i}+\sum_{i=1}^{k} c_{i+4} x_{i}^{2}+\sum_{i=1}^{k-1} \sum_{j>i}^{k} c_{i j} x_{i} y_{j}+\varepsilon
$$

Where, $k$ is the number of process parameters, $k=4$ in this paper. $c_{0}$ is the constant, $c_{i}$ is the coefficient of one degree term, $c_{i+4}$ is the coefficient of the quadratic term, $c_{i j}$ is the coefficient of the interactive

term, $x_{i}$ and $y_{j}$ are independent variables, and $\varepsilon$ is the error of experimental data.

Based on the above model, quadratic regression fitting was performed according to the experimental data in Table 2 , and the second-order response regression equation was obtained by solving:

$$
\begin{aligned}
R a= & 0.314-0.476 R_{t}-2.207 a_{f}-0.255 a_{p}-0.011 \Delta \theta+0.783 R_{t} \bullet a_{f}-0.583 R_{t} \cdot a_{p}+13.563 a_{f} \bullet a_{p}+ \\
& 0.001 R_{t} \bullet \Delta \theta+0.136 a_{f} \bullet \Delta \theta+0.005 a_{p} \bullet \Delta \theta+0.282 R_{t}^{2}+26.281 a_{f}^{2}+6.781 a_{p}{ }^{2}+0.0005 \Delta \theta^{2}
\end{aligned}
$$

\subsection{Model analysis}

The regression equation was analyzed using variance analysis, and the data on variance analysis was obtained, as shown in Table 3. Where, the P-value represents reliability, and $\mathrm{P}=0.05$ is the boundary level of acceptable error (generally $\mathrm{P}<0.05$ indicates the good significance ) [27]. It can be seen from Table 3 that the P-value of the overall model was less than 0.0001 ( $\mathrm{P}<0.0001)$, indicating that the regression model reached an extremely significant level and the error of the whole model was small in the experimental error range. $R^{2}$ of the model was 0.9809 , and adjusted $R^{2}$ of the model was 0.9567 . The difference between the two was very small, and $R^{2}$ was close to 1 , indicating that the model obtained in this experiment had high credibility. The P-value of the lack of fit term of the model was $0.3881(\mathrm{P}>0.05)$, so the lack of fit term was not significant, indicating that the equation was fully fitted and could better describe the real relationship between various factors and response [26-27].

It can be seen from the results of variance analysis in Table 3 that the tool tip radius $\left(R_{t}\right)$ in the one degree terms of the second-order response regression equation had an extremely significant effect on surface roughness $(\mathrm{P}<0.01)$, while the feed rate $\left(a_{f}\right)$ and discrete angle $(\Delta \theta)$ had significant effects on surface roughness $(\mathrm{P}<0.05)$. The order of factors affecting surface roughness was $R_{t}>\Delta \theta>a_{f}>a_{p} \cdot a_{f} \cdot \Delta \theta$ in the interactive terms had a significant effect on surface roughness, $R_{t}^{2}$ in the quadratic terms had an extremely significant effect on surface roughness, $a_{f}{ }^{2}$ had a significant effect, while the rest of the effects were not significant.

\subsection{Reliability test of the model}

It was evident that the significance of the overall model was good after the above significance analysis, so further reliability test of the model was needed. Figure 5(a) shows the relationship between the actural value and the predicted value. It can be seen from the figure that the data fitted by the model were basically around the best simulation curve (i.e., the difference between the predicted value and the actural value was small), indicating that the prediction effect of the model was good. In addition, the residual analysis was carried out. Taking the residual as the abscissa and the 
normal probability as the ordinate, the distribution diagram of residual and normal probability was drawn, as shown in Figure 5(b). It can be seen from the figure that all residual distribution points were basically dis- tributed along a straight line, showing a linear relationship, which met the requirements of normal hypothesis. Most of the test data was distributed in the interval $(-2,2)$ with a confidence level of $95 \%$, indicating that the reliability of the test data was good [27].

Tab. 3 Results of variance analysis

\begin{tabular}{|c|c|c|c|c|c|}
\hline Source & Sum of Squares & Freedom & Mean Square & F-Value & P-Value \\
\hline Model & 0.013 & 14 & $9.431 \times 10^{-4}$ & 40.45 & $<0.0001^{* *}$ \\
\hline$R_{t}$ & $3.735 \times 10^{-3}$ & 1 & $3.735 \times 10^{-3}$ & 160.20 & $<0.0001 * *$ \\
\hline$a_{f}$ & $1.284 \times 10^{-4}$ & 1 & $1.284 \times 10^{-4}$ & 5.51 & $0.0387 *$ \\
\hline$a_{p}$ & $1.715 \times 10^{-6}$ & 1 & $1.715 \times 10^{-6}$ & 0.074 & 0.7913 \\
\hline$\Delta \theta$ & $1.295 \times 10^{-4}$ & 1 & $1.295 \times 10^{-4}$ & 5.55 & $0.0380 *$ \\
\hline$R_{t} \cdot a_{f}$ & $6.123 \times 10^{-5}$ & 1 & $6.123 \times 10^{-5}$ & 2.63 & 0.1334 \\
\hline$R_{t} \cdot a_{p}$ & $3.393 \times 10^{-5}$ & 1 & $3.393 \times 10^{-5}$ & 1.46 & 0.2530 \\
\hline$R_{t} \cdot \Delta \theta$ & $4.516 \times 10^{-6}$ & 1 & $4.516 \times 10^{-6}$ & 0.19 & 0.6684 \\
\hline$a_{f} \cdot a_{p}$ & $2.943 \times 10^{-5}$ & 1 & $2.943 \times 10^{-5}$ & 1.26 & 0.2851 \\
\hline$a_{f} \cdot \Delta \theta$ & $1.183 \times 10^{-4}$ & 1 & $1.183 \times 10^{-4}$ & 5.07 & $0.0457^{*}$ \\
\hline$a_{p} \cdot \Delta \theta$ & $1.806 \times 10^{-7}$ & 1 & $1.806 \times 10^{-7}$ & $7.747 \times 10^{-3}$ & 0.9314 \\
\hline$R_{t}^{2}$ & $5.416 \times 10^{-3}$ & 1 & $5.416 \times 10^{-3}$ & 232.30 & $<0.0001^{* *}$ \\
\hline$a_{f}^{2}$ & $1.206 \times 10^{-4}$ & 1 & $1.206 \times 10^{-4}$ & 5.17 & $0.0440 *$ \\
\hline$a_{p}^{2}$ & $8.027 \times 10^{-6}$ & 1 & $8.027 \times 10^{-6}$ & 0.34 & 0.5692 \\
\hline$\Delta \theta^{2}$ & $7.448 \times 10^{-5}$ & 1 & $7.448 \times 10^{-5}$ & 3.19 & 0.1015 \\
\hline Lack of Fit & $2.496 \times 10^{-4}$ & 10 & $2.496 \times 10^{-5}$ & 3.65 & 0.3881 \\
\hline Residual & $2.565 \times 10^{-4}$ & 11 & $2.332 \times 10^{-5}$ & - & - \\
\hline Pure Error & $6.845 \times 10^{-6}$ & 1 & $6.845 \times 10^{-6}$ & - & - \\
\hline Total & 0.013 & 25 & - & - & - \\
\hline
\end{tabular}

Remarks: * represents significant, ** represents extremely significant. $R^{2}=0.9809$, adjusted $R^{2}=0.9567$.
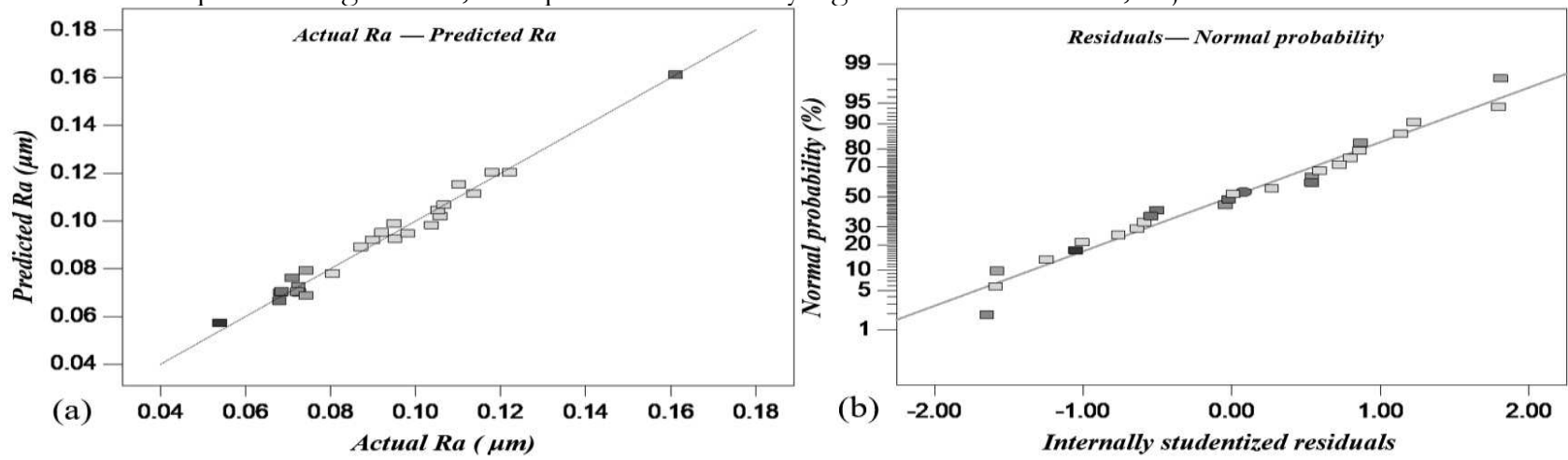

Fig. 5 Reliability test of the model, (a) Relationship between the actural value and the predicted value, (b) Distribution diagram of residual and normal probability

In order to check the actual prediction effect of the above regression model, three groups of process parameters were randomly selected for processing and the surface roughness was measured. Comparing the predicted value and the actual value of the surface rou- ghness, the prediction error of the model was obtained, and the results are shown in Table 4 . It can be seen that under the three groups of process parameters, the maximum prediction error was $8.3 \%$, and the average prediction error was $7.6 \%$. The results 
showed that the regression model can be used to predict the surface roughness of toric surface accurately, and the model can be used as the objective function to optimize the process parameters.

Tab. 4 Comparison between predicted results and experimental results

\begin{tabular}{ccccccccc}
\hline Number & $R_{t}(\mathrm{~mm})$ & $a_{f}(\mathrm{~mm} / \mathrm{r})$ & $a_{p}(\mathrm{~mm})$ & $\Delta \theta\left(^{\circ}\right)$ & $\begin{array}{c}\text { Predicted } \\
\text { value }\end{array}$ & $\begin{array}{c}\text { Actual } \\
\text { value }\end{array}$ & $\begin{array}{c}\text { Prediction } \\
\text { error }\end{array}$ & $\begin{array}{c}\text { Average } \\
\text { prediction } \\
\text { error }\end{array}$ \\
\hline 1 & 0.25 & 0.03 & 0.03 & 4 & 0.1641 & 0.1777 & $8.3 \%$ & \\
2 & 0.75 & 0.01 & 0.04 & 8 & 0.0538 & 0.0578 & $7.4 \%$ & $7.6 \%$ \\
3 & 1.00 & 0.03 & 0.03 & 4 & 0.0790 & 0.0847 & $7.2 \%$ & \\
\hline
\end{tabular}

\section{Process parameters optimization}

The best process parameters can improve the processing quality or efficiency, which has practical significance for guiding production, so it is necessary to optimize the process parameters. PSO is a new intelligent optimization algorithm, which has the advantages of high precision, fast convergence speed, and easy programming. At present, it is widely used in natural and engineering fields such as function optimization, neural network optimization training, and combinatorial optimization [28-30]. Therefore, it can be applied to the process parameters optimization of surface roughness.

\subsection{Optimization with standard PSO}

Based on swarm intelligence theory, PSO is usually used to solve the problem of optimization. In this algorithm, the solution of each optimization problem can be regarded as a particle in the search space, and all particles constitute a particle swarm. Each particle has attributes such as position, velocity, and fitness. The position represents a point in the solution space, and velocity represents the direction and distance of particle movement. The fitness value is calculated by the fitness function, which is used to evaluate the position of particles. The initial position, velocity and fitness of each particle are set randomly. With the iterative process, the velocity and position of each particle are constantly updated by following the individual extremum $p_{i}^{k}$ and group extremum $g^{k}$. Individual extremum $p_{i}{ }^{k}=\left(p_{i 1}{ }^{k}, p_{i 2}{ }^{k}, \cdots, p_{i N}{ }^{k}\right)$ refers to the optimal position of particle $i$ from the initial to No. k iteration. Group extremum $g^{k}=\left(g_{1}{ }^{k}, g_{2}{ }^{k}, \cdots, g_{N}{ }^{k}\right)$ refers to the optimal position of the whole group from the initial to No. $\mathrm{k}$ iteration. $\mathrm{N}$ is the dimension of the particles, namely the number of process parameters that need to be optimized, so $\mathrm{N}=4$. The updating formula of velocity and position of the particles is as follows [31]:

$$
\left\{\begin{array}{l}
v_{i n}{ }^{k+1}=\omega v_{i n}{ }^{k}+c_{1} r_{1}\left(p_{i n}{ }^{k}-x_{i n}{ }^{k}\right)+c_{2} r_{2}\left(g_{n}{ }^{k}-x_{i n}{ }^{k}\right) \\
x_{i n}{ }^{k+1}=x_{i n}{ }^{k}+v_{i n}{ }^{k+1}
\end{array}\right.
$$

Where, $v_{i n}{ }^{k}$ and $x_{i n}{ }^{k}$ are the velocity and position of the No. i $(1 \leq i \leq M)$ particle in the No. $\mathrm{n}$ $(1 \leq n \leq N)$ dimension space in the No. $\mathrm{k}(1 \leq k \leq K)$ iteration, respectively. In order to prevent the blind search of the particles, the position and speed of the particles are usually limited within a certain range:

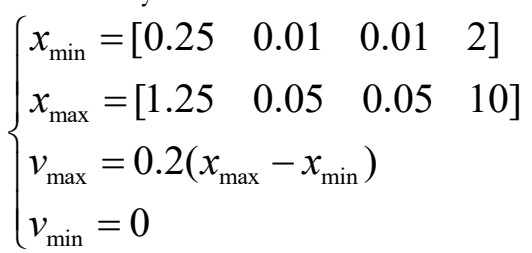

$M$ and $K$ represent the set population size and the maximum number of iterations, respectively, taking $M=24$ and $K=250 . r_{1}$ and $r_{2}$ are random numbers distributed in the interval $(-1,1)$ generated by rand function, $c_{1}$ and $c_{2}$ are learning factors, and $\omega$ is inertia weight. $\omega$ determines the extent to which the particles inherit the previous flight speed. Reasonable selection of $\omega$ can achieve the balance between global search and local search. Most studies show that the algorithm has good global search ability and can quickly locate the region close to the global optimal solution by setting a large value of $\omega$ at the beginning of the iteration. By reducing the value of $\omega$ at the later stage of iteration, the algorithm has good local search ability, so as to quickly obtain the accurate global optimal solution [30-31]. Therefore, linear decreasing weight method was used to set $\omega$ [32]:

$$
\omega(k)=\omega_{\text {start }}-\left(\omega_{\text {start }}-\omega_{\text {end }}\right)\left(\frac{k}{K}\right)^{2}
$$

Where, $\omega_{\text {start }}$ is the initial inertia weight $\left(\omega_{\text {start }}=0.9\right), \omega_{\text {end }}$ is the ending inertia weight $\left(\omega_{\text {end }}=0.4\right), k$ is the current iteration number, and $K$ is the maximum iteration number. In order to describe the optimization process of PSO better, the flow chart of PSO was established, as shown in Figure 6. 
Although the standard PSO has fast convergence speed, it is easy to fall into the local optimal position.

The unreasonable selection of learning factors $\left(c_{1}, c_{2}\right)$ is an important reason for it to fall into the local optimal position [33]. According to Formula (7), $v_{i n}{ }^{k+1}=\omega v_{i n}{ }^{k}+c_{2} r_{2}\left(g_{n}{ }^{k}-x_{i n}{ }^{k}\right)$, when $c_{1}=0$. It shows that the particles search the goal through the optimal global information at this time, but in the case of lack of individual cognition, the particles cannot find the optimal solution in the local area. $v_{\text {in }}{ }^{k+1}=\omega v_{\text {in }}{ }^{k}+c_{1} r_{1}\left(p_{\text {in }}{ }^{k}-x_{\text {in }}{ }^{k}\right)$, when $c_{2}=0$. It shows that the particles have the ability of local optimization, but only when the particle swarm can search the global optimal region, local search can find the optimal solution, otherwise it is easy to fall into local optimum. In addition, when $c_{1}$ and $c_{2}$ are too large, the particles will converge to the local optimum prematurely [33].

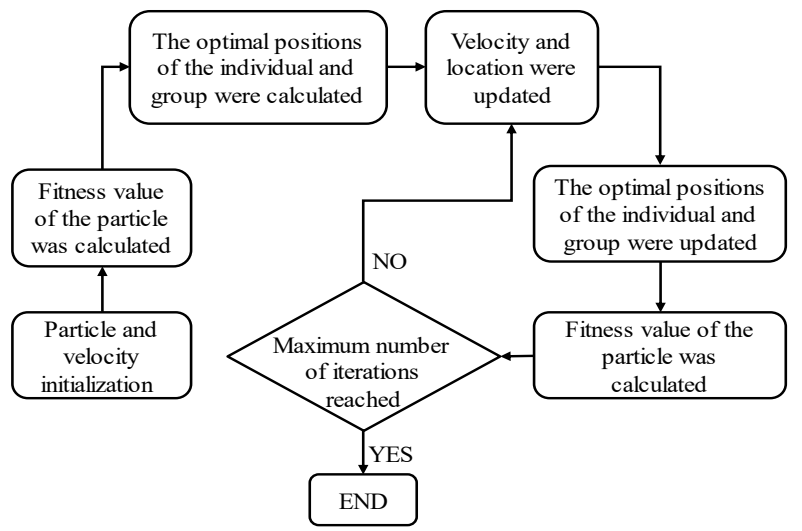

Fig. 6 Flow chart of PSO

Equation (6) was used as the fitness function (test_func) of standard PSO (Common PSO), and the corresponding program of standard PSO was written using Matlab. When $c_{1}=0$ and $c_{2}=0,250$ iterations were performed, and the result was shown in Figure 7(a). When $c_{1}$ and $c_{2}$ were larger, $c_{1}=10$ and $c_{2}=10$ were taken, the same method was adopted and the result was shown in Figure 7(b). It can be seen from Figure 7 that the optimal individual fitness value obtained by standard PSO was 0.0555 when $c_{1}=0$ and $c_{2}=0$, and the corresponding position of the particle was $(0.90,0.01$, $0.01,9.46)$. That is, when $R_{t}=0.90 \mathrm{~mm}, a_{f}=0.01 \mathrm{~mm} / r$ , $a_{p}=0.01 \mathrm{~mm}$, and $\Delta \theta=9.46^{\circ}$, the surface roughness of the machined toric surface was the lowest at 0.0555 $\mu \mathrm{m}$. When $c_{1}$ and $c_{c_{2}}$ were larger, the optimal individual fitness value was 0.0503 , and the corresponding position of the particle was $(0.83,0.01,0.03,8.54)$.

That is, when $R_{t}=0.83 \mathrm{~mm}, a_{f}=0.01 \mathrm{~mm} / \mathrm{r}$, $a_{p}=0.03 \mathrm{~mm}$, and $\Delta \theta=8.54^{\circ}$, the surface roughness of the machined toric surface was the lowest at 0.0503 $\mu \mathrm{m}$. Through comparison and analysis, it can be seen that the optimization results obtained by standard PSO were quite different when the values of learning factors selected were different. In addition, from the particle dynamics model in Figure 7, it can be seen that the final particle swarms under different learning factors were both relatively dispersed, and neither of them reached the global optimal position. This indicates that the global optimization ability of standard PSO was poor (i.e., poor convergence), and it would fall into the local optimal position when $c_{1}$ and $c_{2}$ were too small or large, which explains the reason for the large difference between the two optimization results. Therefore, the best combination of process parameters of the above mathematical model cannot be obtained by the standard PSO.

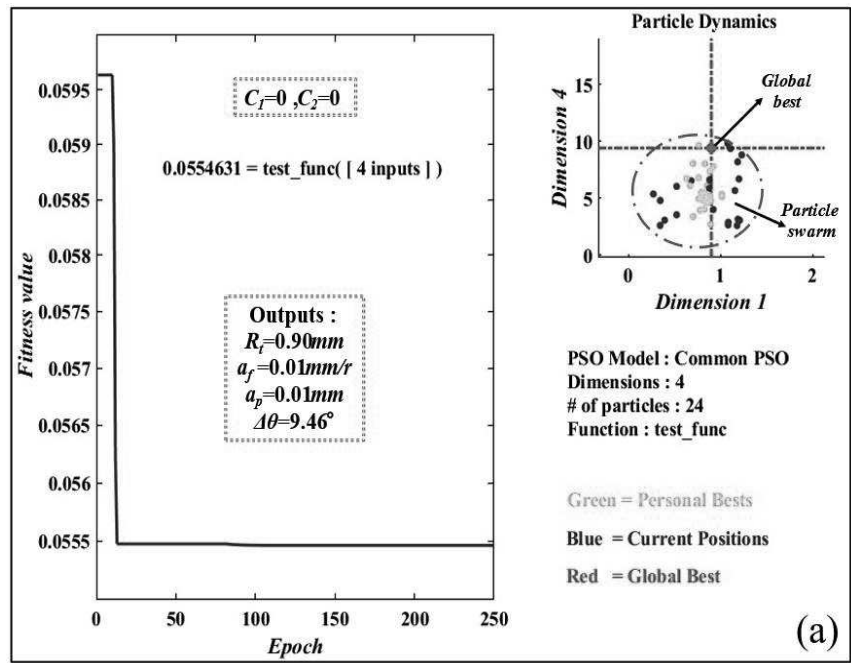

Fig. 7 Optimization results of standard PSO, (a) Optimization result ( $c_{1}=0, c_{2}=0$ ), (b) Optimization result $\left(c_{1}=10, c_{2}=10\right.$ ) 


\subsection{Optimization with WCF-PSO}

The learning factors $\left(c_{1}, c_{2}\right)$ determined the influence of the experience information between the particles on the trajectory of the particles, which reflected the information exchange between the particle swarm. Through the above analysis and optimization, it was found that if the values of learning factors $\left(c_{1}, c_{2}\right)$ were different, the optimization results were quite different. In addition, when the values of learning factors $\left(c_{1}, c_{2}\right)$ were unreasonable, it can be known from the above particle dynamics model that the convergence of the algorithm would be poor and therefore easy to fall into the local optimal position.

In order to solve the above problems, the standard PSO was improved. By adjusting the learning factors reasonably to control the flying speed of particles effectively, the algorithm can achieve an effective balance between global optimization and local optimization. The introduction of compression factor $(\varphi)$ can effectively adjust the parameters in the formula of particle velocity and position, so as to ensure the convergence of the PSO. After introducing the compression factor $(\varphi)$, the particle swarm optimization with compression factor (WCF-PSO) was constructed, and the updating formula of velocity and position of the particles was changed to [34]:

$$
\left\{\begin{array}{l}
v_{i n}{ }^{k+1}=\varphi \cdot\left[\omega v_{i n}{ }^{k}+c_{1} r_{1}\left(p_{i n}{ }^{k}-x_{i n}{ }^{k}\right)+c_{2} r_{2}\left(g_{n}{ }^{k}-x_{i n}{ }^{k}\right)\right] \\
\varphi=\frac{2}{\left|2-C-\sqrt{C^{2}-4 C}\right|}, \quad\left(C=c_{1}+c_{2}\right)
\end{array}\right.
$$

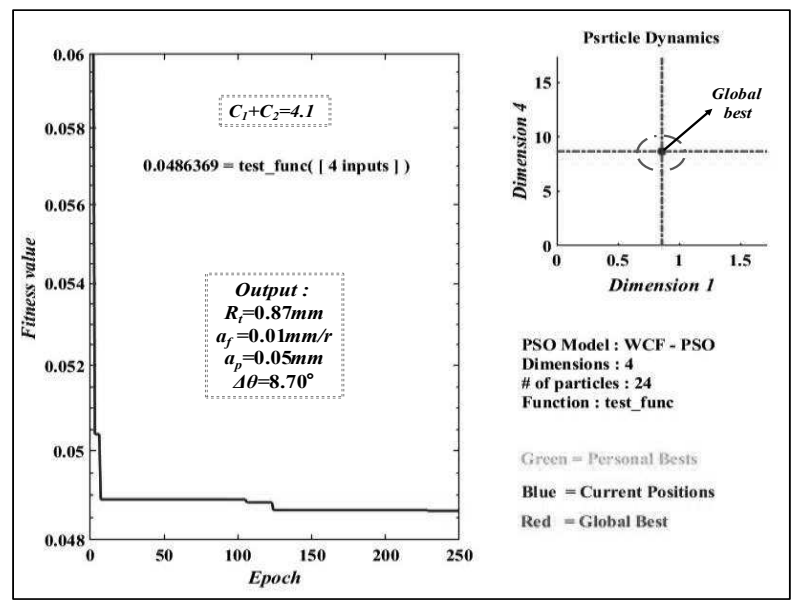

Fig. 8 Optimization result under WCF-PSO

According to the study, $c_{1}+c_{2}=4.1_{\text {was taken [34], }}$ and compression factor $(\varphi)$ was 0.73 at this time. A total of 250 iterations were carried out to obtain the optimization result, as shown in Figure 8. It can be seen from the figure that the final optimal individual fitness value obtained by WCF-PSO was 0.0486 , and the corresponding position of the particle was $(0.87,0.01$, $0.05,8.70)$. That is, when $R_{t}=0.87 \mathrm{~mm}, a_{f}=0.01 \mathrm{~mm} / \mathrm{r}$ , $a_{p}=0.05 \mathrm{~mm}$, and $\Delta \theta=8.70^{\circ}$, the surface roughness of the machined toric surface was the lowest at $0.0486 \mu \mathrm{m}$. In addition, by comparing Figure 7 and Figure 8 , the particle dynamics model was analyzed. It can be seen that after 250 iterations, the final particle swarm was dispersed under the standard PSO, and the global optimal position was not found, indicating that the global optimization ability of the algorithm was poor and the algorithm fell into local optimal position easily. After 250 iterations, the final particle swarm converged at a point under the improved WCF-PSO, indicating that the optimal position was found in the global range. It showed that compared with the standard PSO, the improved WCF-PSO had better global search ability and better optimization effect.
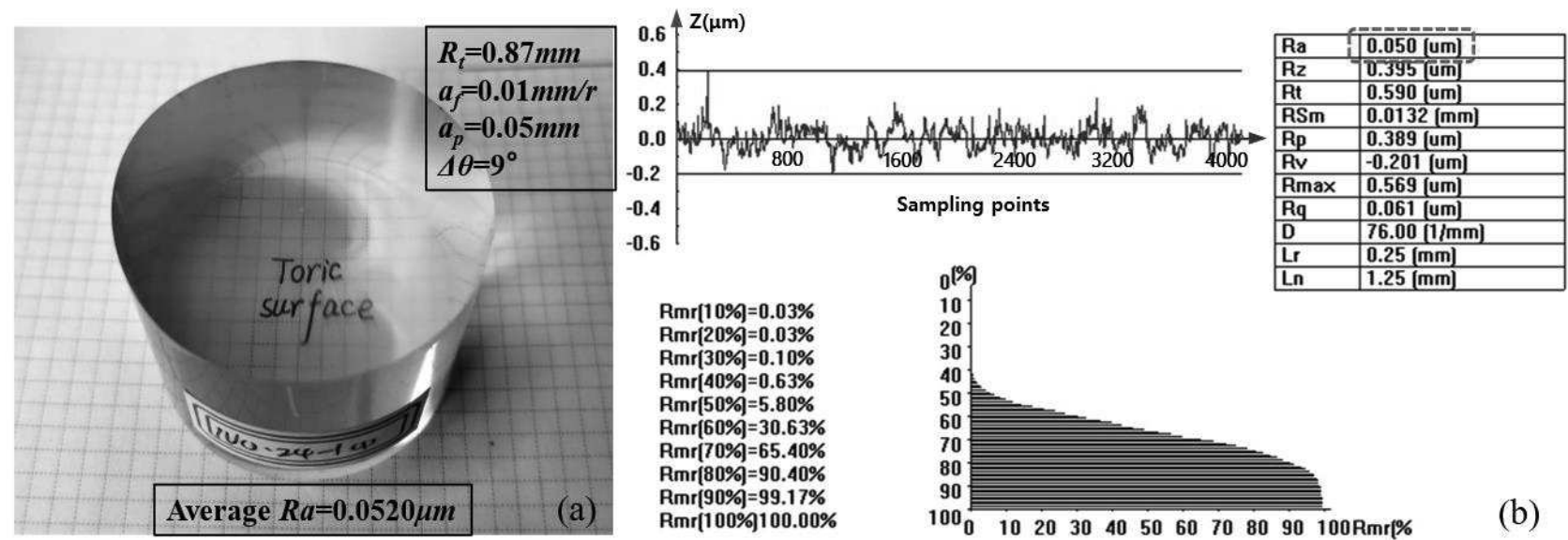

$\operatorname{Rmr}[10 \%=0.03 \%$ mr $20 \%]=0.03 \%$ $\operatorname{Rmr}[30 \%]=0.10 \%$ $\operatorname{Rmr}[50 \%]=5.80 \%$ $\operatorname{Rmr}[60 \%)=30.63 \%$
$\operatorname{Rmr}[70 \%]=65.40 \%$ $\operatorname{Rmr}[80 \%=90.40 \%$ Rmr(100\% $100.00 \%$

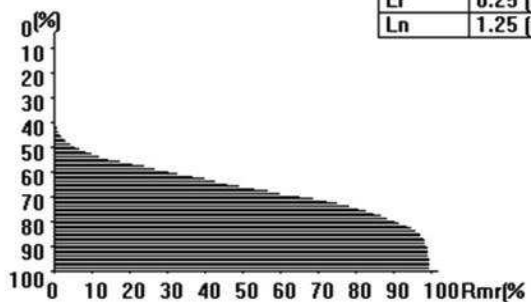

(b)

Fig. 9 Workpiece of toric surface and the value of $\mathrm{R}$ a of a part on it (Optimization by WCF-PSO), (a) Machined workpiece of toric surface, (b) The value of $\mathrm{R}$ a of a part on the toric surface 
In order to test the accuracy of the optimization result uner WCF-PSO, it was necessary to verify it by carrying out process test. In order to facilitate the test, the process parameters obtained by WCF-PSO were properly adjusted, $\Delta \theta=9^{\circ}$ was taken, and the other parameters remained unchanged. The machined workpiece of toric surface is shown in Figure 9(a), and its surface roughness was measured. The measurement method was the same as above. The final measurement result was $R a=0.0520 \mu \mathrm{m}$, and Figure 9(b) shows the value of $R a$ of a part on the toric surface (In the roughness profile graph, the abscissa represents sampling points and ordinate represents the $Z$ value of the workpiece surface). Compared with the optimization result $(R a=0.0486 \mu m)$ under WCF-PSO, the error was only $7.0 \%$, indicating that the WCF-PSO proposed in this paper had a better optimization effect.

\section{Conclusions}

(1) RSM was used to design the experiment, the second-order response surface model was obtained and the variance analysis and reliability test of the mathematical model were carried out. The analysis results showed that the P-value of the overall model was less than $0.0001(\mathrm{P}<0.0001)$, indicating that the model reached an extremely significant level. $R^{2}$ of the model was 0.9809 , which was close to 1 , indicating that the model had high credibility. Most of the test data was distributed in the interval $(-2,2)$ with a confidence level of $95 \%$, indicating that the reliability of the test data was good. The results of the verification test showed that the average prediction error of the model was $7.6 \%$, which can accurately predict the surface roughness and be taken as the objective function to optimize the process parameters.

(2) PSO can be used to optimize the process parameters of surface roughness in STS turning. However, if the selection of learning factors is unreasonable, it is easy to cause the standard PSO to fall into local optimal position. When $c_{c_{1}}$ and $c_{2}$ were too small $\left(c_{1}=0\right.$, $c_{2}=0$ ), after 250 iterations, the minimum value of $R a$ was $0.0555 \mu \mathrm{m}$ and the corresponding best combination of process parameters was: $R_{t}=0.90 \mathrm{~mm}$, $a_{f}=0.01 \mathrm{~mm} / r, a_{p}=0.01 \mathrm{~mm}, \Delta \theta=9.46^{\circ}$. When $c_{1}$ and $c_{2}$ were too large $\left(c_{1}=10, c_{2}=10\right)$, after 250 iterations, the minimum value of $R a$ was $0.0503 \mu \mathrm{m}$ and the corresponding best combination of process parameters was: $R_{t}=0.83 \mathrm{~mm}, a_{f}=0.01 \mathrm{~mm} / r, a_{p}=0.03 \mathrm{~mm}$, $\Delta \theta=8.54^{\circ}$. The optimization results of the standard PSO showed that if the learning factors were too small or large, the results of the standard PSO were quite different and the algorithm would fall into the local optimal position.

(3) By introducing compression factor $(\varphi), \mathrm{WCF}$ PSO was constructed, which made PSO achieve an effective balance between global detection and local detection. Under WCF-PSO, after 250 iterations, the minimum value of $R a$ was $0.0486 \mu \mathrm{m}$ and the corresponding best combination of process parameters was: $R_{t}=0.87 \mathrm{~mm}, a_{f}=0.01 \mathrm{~mm} / r, a_{p}=0.05 \mathrm{~mm}$, $\Delta \theta=8.70^{\circ}$. After verified test, the results showed that the error between the optimization result and the experimental result was only $7.0 \%$, indicating that the WCF-PSO proposed in this paper has a better optimization effect.

\section{Acknowledgement}

Project supported by Jiangsu graduate research
and practice innovation program (KYCX19 0607)

\section{References}

[1] YAMAMOTO T, MASTUDA R, SHINDOU M, et al. (2021). Monitoring of Vibrations in Free-form Surface Processing Using Ball Nose End Mill Tools with Wireless Tool Holder Systems. In: Int J Adv Manuf Tech, Vol. 15, pp. 335342. Springer. Germany. ISSN

[2] NAGAYAMA K, YAN J (2021). Deterministic Error Compensation for Slow Tool Servo-driven Diamond Turning of Freeform Surface with Nanometric Form Accuracy. In: Journal of Manufacturing Processes, Vol. 64, pp. 45-47. United States. ISSN

[3] ZHOU X D, HUANG X, BAI J, et al. (2019). Representation of Complex Optical Surfaces with Adaptive Radial Basis Functions. In: $A p$ plied Optics, Vol. 58, pp. 3938-3944. United States. ISSN

[4] FARSKÝ J, ZETEK M, BAKŠA T, et al. (2020). Effect of the Cutting Conditions on Surface Roughness During 5-axis Grinding of Maraging Steel MS1. In: Manufacturing Technology, Vol. 20, No. 4, pp. 423-428. ISSN

[5] SADÍLEK M, KOUSAL L, NÁPRSTKOVÁ $\mathrm{N}$, et al. (2018). The Analysis of Accuracy of Machined Surfaces and Surfaces Roughness after 3 Axis and 5 Axis Milling. In: Manufacturing Technology, Vol. 18, NO. 6, pp. 1015-1022. ISSN

[6] TUONG N V, NATASA N (2019). Matlabbased Calculation Method for Partitioning a 
Free-form Surface into Regions. In: Manufacturing Technology, Vol. 19, NO. 3, pp. 518-524. ISSN

[7] QIU X Y, ZHANG Y Q, WANG H B (2020). Tool Path Planning Method for Slow Tool Servo Machining of Toric Surface. In: Journal of National University of Defense Technology, Vol. 42, pp. 121-127. China. ISSN.

[8] PEI X N, JI Z, SHI J J, et al. (2020). Ultra-precision Machining of a Large Amplitude Umbrella Surface Based on Slow Tool Servo. In: International Journal of Precision Engineering and Manufacturing, Vol. 21, pp. 1-12. South Korea. ISSN

[9] WANG D F (2020). Research on the Key Technologies for Ultra Precision Turning of Large Aperture Free-form Surfaces. Ph.D thesis, University of Chinese Academy of Sciences (Changchun Institute of Optics, Fine Mechanics and Physics, Chinese Academy of Sciences), Changchun, China. ISSN

[10] DONG Q Q (2020). Research on the Key Technologies of Slow Tool Servo Turning. Master degree thesis, Changchun University of Technology, Changchun, China. ISSN

[11] WANG R H, WANG Z H (2021). Analysis of Milling Force and Surface Roughness of $\mathrm{TC}_{4}$ Titanium Alloy. In: Tool Engineering, Vol. 55, pp. 30-33. China. ISSN

[12] LIN Z Q, CHEN X D, YAN Z T, et al. (2020). Prediction Model of Surface Roughness for Slow Tool Servo Machining of Microlens Array. In: Journal of Harbin University of Science and Technology, Vol. 25, pp. 83-87. China. ISSN

[13] WANG X S, KANG M, FU X Q, et al. (2013). Prediction of Surface Roughness of Lens Precision Turning. In: Journal of Mechanical Engineering, Vol. 49, pp. 192-198. China. ISSN

[14] SHI W T, LIU Y D, WANG X B, et al. (2010). Surface Roughness Prediction and Experiment of Micro Milling. In: Transactions of The Chinese Society of Agricultural Machinery, Vol. 41, pp. 211-215. China. ISSN

[15] JIANG Z Q, KONG J X, ZHENG M (2010). Study on Surface Roughness and Machining Residual Stress of PCD Tool Precision Cutting Pure Copper Material. In: Tool Engineering, Vol. 55, pp. 24-29. China. ISSN

[16] LI C L, KANG M, WANG X S, et al. (2015). Surface Roughness Prediction and Parameter
Optimization of Optical Lens Precision Turning. In: Piezoelectrics \& Acoustooptics, Vol. 37, pp. 796-801. China. ISSN

[17] HE Z, ZONG Z Y, KONG X F (2006). Application of Improved Satisfaction Function Method in Multi-response Optimization. In: Journal of Tianjin University, Vol. 9, pp. 11361140. China. ISSN

[18] WEI H X, SHEN J B, WANG H T (2017). Location and Size Optimization of Piezoelectric Patch Based on Standard PSO Algorithm. In: Applied Science and Technology, Vol. 44, pp. 62-69. China. ISSN

[19] ZHAO L, CHENG K, DING H, et al. (2020). Research on the Key Technological Problems of Ultra Precision Slow Tool Servo Diamond Turning. In: Manufacturing Technology \& Machine Tool, Vol. 5, pp. 85-88. China. ISSN

[20] WANG X S (2014). Research on the Key Technologies of Slow Tool Servo Turning for Complex Optical Surface. Ph.D thesis, Nanjing Agriculture University, Nanjing, China. ISSN

[21] ZHANG Q, XUE C X (2020). Trajectory Optimization for Slow Tool Servo Turning of Free-form Surfaces. In: Laser \& Optoelectronics Progress, Vol. 57, pp. 233-239. China. ISSN

[22] CHEN X (2016). Research on PID Parameter Optimization and Tool Path Generation of Slow Tool Servo Turning Machine. Master degree thesis, Nanjing Agriculture University, Nanjing, China. ISSN

[23] NIU H T (2018). Research on Slow Tool Servo Turning and Form Accuracy Measuring for Complex Surface. Master degree thesis, Nanjing Agriculture University, Nanjing, China. ISSN

[24] MA R B, DONG L H, WANG H D, et al. (2017). Research on Contact Fatigue Life Prediction of Thermal Spray Coating Based on Central Composite Design. In: Acta Armamentarii, Vol. 38, pp. 561-567. China. ISSN

[25] XIE J, LIAO Y H, TAN Z, et al. (2021). Multi Objective Optimization Design of Tool Grinder Column Based on Response Surface Model and Genetic Algorithm. In: Manufacturing Technology \& Machine Tool, Vol. 4, pp. 48-54. China. ISSN

[26] TIE Z M (2021). Die Wear of Sheet Metal Stamping Based on Response Surface Method. In: Forging and Stamping Technology, Vol. 46, pp. 174-178. China. ISSN 
[27] PANDA J N, ORQUERA E Y, WONG B C, et al. (2021). Prediction of Optimal Process Parameters in Tribocorrosion Inhibition of Steel Pipes Using Response Surface Methodology. In: Tribology Letters, Vol. 69, pp. 73-77. United States. ISSN

[28] WANG H, CAI T, LI K S, et al. (2021). Constraint Handling Technique Based on Lebesgue Measure for Constrained Multiobjective Particle Swarm Optimization Algorithm. In: Knowledge-Based Systems, Vol. 227, pp. 107-131. Elsevier. Netherlands. ISSN

[29] QIAO L, WANG Z B, WANG Y, et al. (2020). Mechanical Performance Based Optimum Design of High Carbon Pearlitic Steel by Particle Swarm Optimization. In: Steel Research International, Vol. 92, pp. 242-252. Germany. ISSN

[30] SHUO M, JIAN S K, KUO C, et al. (2020). Gearbox Fault Diagnosis Through Quantum Particle Swarm Optimization Algorithm and Kernel Extreme Learning Machine. In: Journal of Vibroengineering, Vol. 22, pp. 1399-1414. Lithuania. ISSN

[31] ZHENG G, LIU S M, WANG D S, et al. (2020). Optimization of Cold Extrusion Process for Filter Shell Based on Response Surface Method and Particle Swarm Optimization. In: Intelligent computer and applications, Vol. 10, pp. 199-202 + 205. China. ISSN

[32] QIN L X, ZHANG K, WANG Y B, et al. (2020). Fault Diagnosis Method of Diesel Engine Based on Optimized PSO-RBF. In: Diesel Engine, Vol. 42, pp. 23-28. China. ISSN

[33] YU W W, SHEN Y, XU X L, et al. (2020). Simulation and Research on PID Parameter Tuning Based on PSO. In: Journal of Chongqing University of Technology and Industry, Vol. 37, pp. 14-19. China. ISSN

[34] WANG C, HAN J H, JI Q (2021). Optimization Design of Gear Transmission Based on Improved Particle Swarm Optimization. In: Journal of Mechanical \& Electrical Engineering, Vol. 38, pp. 239-244. China. ISSN 